\title{
Life cycle assessment and costing of urine source separation: Focus on nonsteroidal anti- inflammatory drug removal
}

\author{
Kelly A. Landry*,a and Treavor H. Boyer ${ }^{\mathrm{b}}$ \\ ${ }^{a}$ Department of Environmental Engineering Sciences \\ Engineering School of Sustainable Infrastructure \& Environment \\ University of Florida \\ P.O. Box 116450 \\ Gainesville, Florida 32611-6450, USA \\ ${ }^{\mathrm{b}}$ School of Sustainable Engineering and the Built Environment \\ Arizona State University \\ PO Box 873005, Tempe, AZ 85287-3005, USA \\ *Corresponding author. \\ Tel.: 1-352-514-9129; fax: 1-352-392-3076. \\ E-mail addresses: klandry@ufl.edu (K.A. Landry); thboyer@asu.edu (T.H. Boyer).
}

Submitted to

Water Research

13 April 2016 


\section{ABSTRACT}

2 Urine source separation has the potential to reduce pharmaceutical loading to the environment,

3 while enhancing nutrient recovery. The focus of this life cycle assessment (LCA) was to evaluate

4 the environmental impacts and economic costs to manage nonsteroidal anti-inflammatory drugs

5 (NSAIDs) (i.e., diclofenac, ibuprofen, ketoprofen and naproxen) and nutrients in human urine.

6 Urine source separation was compared with centralized wastewater treatment (WWT) (biological

7 or upgraded with ozonation). The current treatment method (i.e., centralized biological WWT)

8 was compared with hypothetical treatment scenarios (i.e., centralized biological WWT upgraded

9 with ozonation, and urine source separation). Alternative urine source separation scenarios

10 included varying collection and handling methods (i.e., collection by vacuum truck, vacuum

11 sewer, or decentralized treatment), pharmaceuticals removal by ion-exchange, and struvite

12 precipitation. Urine source separation scenarios had $90 \%$ lower environmental impact (based on

13 the TRACI impact assessment method) compared with the centralized wastewater scenarios due

14 to reduced potable water production for flush water, reduced electricity use at the wastewater

15 treatment plant, and nutrient offsets from struvite precipitation. Despite the greatest reduction of

16 pharmaceutical toxicity, centralized treatment upgraded with ozone had the greatest ecotoxicity

17 impacts due to ozonation operation and infrastructure. Among urine source separation scenarios,

18 decentralized treatment of urine and centralized treatment of urine collected by vacuum truck

19 had negligible cost differences compared with centralized wastewater treatment. Centralized

20 treatment of urine collected by vacuum sewer and centralized treatment with ozone cost $30 \%$

21 more compared with conventional wastewater treatment.

22 Keywords: Life cycle assessment; life cycle costing; urine source separation; nonsteroidal anti-

23 inflammatory drugs; ion-exchange; wastewater treatment 


\section{1. Introduction}

25 Approximately 64\% of ingested pharmaceuticals intended for human use are excreted in urine as

26 the parent compound or metabolites (Lienert et al., 2007a). Human urine is the primary

27 contributor of pharmaceuticals in municipal wastewater but only constitutes $1 \%$ of the total

28 volumetric flow (Joss et al., 2005, Larsen and Gujer, 1996). Urine source separation has been

29 proposed as a more efficient method to remove and/or destroy pharmaceuticals as opposed to

30 centralized biological wastewater treatment because pharmaceuticals are present at much higher

31 concentrations in undiluted urine (Lamichhane and Babcock, 2012). In addition, human urine

32 contributes $80 \%$ of the nitrogen $(\mathrm{N})$ and $50 \%$ of the phosphorus $(\mathrm{P})$, indicating separate

33 treatment of urine may have significant impacts on centralized wastewater treatment (Larsen and

34 Gujer, 1996). Furthermore, human urine may be utilized as an alternative fertilizer source

35 because $\mathrm{N}$ and $\mathrm{P}$ are essential nutrients used in agriculture (Kirchmann and Pettersson, 1995).

36 Therefore, effective separation of pharmaceuticals from nutrients is necessary to obtain a

37 "contaminant free" nutrient product. From previous research, sorption processes are an effective

38 method to selectively remove nonsteroidal anti-inflammatory drugs (NSAIDs) from urine with

39 minimal co-sorption of nutrients, and may be effectively regenerated using a 5\% sodium

40 chloride, 50\% methanol solution (Landry and Boyer, 2013, Landry et al., 2015). Furthermore,

41 sorption is attractive for pharmaceutical removal because it is low energy and has different

42 treatment configurations such as fixed-bed or mixed reactors, continuous flow or batch, and

43 sorbent regeneration or disposal (Crittenden et al., 2012). The basis of this research is that

44 removing pharmaceuticals from undiluted urine would be more effective and efficient than in

45 centralized wastewater, particularly for pharmaceuticals primarily excreted in urine (Lienert et 
al., 2007a, Winker et al., 2008a), however, the environmental impacts of using sorption

47 processes to remove pharmaceuticals in urine is unknown.

Life cycle assessment (LCA) applied to urine source separation is an emerging research

49 area with only one study considering removal of pharmaceuticals. The primary focus of several

50 papers included the source separation system (i.e., urine piping, collection, and storage), fertilizer

51 offsets, wastewater treatment offsets, and potable water offsets (Ishii and Boyer, 2015, Lam et

52 al., 2015, Maurer et al., 2003, Remy, 2010). Remy (2010) conducted an LCA that included an

53 ozonation process for pharmaceutical destruction in source separated urine, however they did not

54 evaluate the specific toxicity of pharmaceuticals in the model. Previous LCA studies have

55 evaluated the environmental impacts of pharmaceuticals in wastewater effluent. A study by

56 Muñoz et al. (2008) concluded that pharmaceuticals were a significant contributor to the toxicity

57 of the studied wastewater. Conversely, it was found that pharmaceuticals in decentralized

58 hospital wastewater exhibited negligible environmental impact compared with the impacts

59 generated by wastewater treatment (Igos et al., 2013, Igos et al., 2012). Advanced treatment of

60 decentralized hospital wastewater would not decrease pharmaceutical toxicity in total wastewater

61 effluent because the contribution of pharmaceuticals from hospital wastewater was much smaller

62 than other sources (e.g., pharmaceutical usage at homes, office buildings, etc.) (Igos et al., 2012).

63 Ort et al. (2010) estimated that hospital wastewater contributed 15\% of pharmaceuticals to

64 centralized wastewater. This suggests that an alternative approach to treating municipal

65 wastewater at the community-level, such as urine source separation, could be more effective at

66 reducing pharmaceutical loading to the environment. To date, there is not a published LCA study

67 on urine source separation considering removal of pharmaceuticals by sorption process and

68 corresponding reduction in toxicity. The goal of this research was to compare the overall 
69 environmental and economic impacts of pharmaceutical removal from urine generated in a

70 university community by centralized wastewater treatment, advanced treatment of centralized

71 wastewater, and centralized and decentralized treatment of source separated urine. The

72 pharmaceuticals investigated in this study were from the NSAID pharmaceutical class and

73 included diclofenac (DCF), ibuprofen (IBP), ketoprofen (KTP), and naproxen (NPX). They were

74 selected because of high ecotoxicity potential, prevalence, and variable removal rates in

75 biological wastewater treatment (Hernando et al., 2006, Lienert et al., 2007b, Verlicchi et al.,

76 2012). For the reasons given above, NSAIDs have been the focus of ion-exchange removal

77 studies in urine. This study utilizes lab-scale experimental data to build a robust framework and

78 conduct a baseline assessment that may be augmented with new pharmaceutical adsorption data

79 as it becomes available.

\section{2. Life cycle model}

\section{2.1. Scope of the study}

82 The functional unit for this study was the conveyance, storage, pharmaceutical management (i.e.,

83 ion-exchange treatment), and nutrient management (i.e., struvite precipitation) of $11,184 \mathrm{~m}^{3}$ of

84 urine, which is equivalent to the estimated annual production of urine at the University of Florida

85 (UF) campus in Gainesville, Florida, USA. This study builds upon the LCA model developed by

86 Ishii and Boyer (2015) by expanding the system boundary from residence halls to include the

87 entire UF campus, and pharmaceutical management. Detailed calculations used to determine the

88 functional unit are provided in the Supplementary Material 1 (SM1, section S1).

89 Figure 1 shows the wastewater management scenarios considered in this LCA. Scenario

90 Awwt serves as the baseline scenario and included combined collection of urine, feces, and

91 greywater, and biological treatment at the UF Water Reclamation Facility. The upstream system 
92 boundary includes operational inputs for potable flush water production at the nearby drinking

93 water treatment facility. The construction and decommission phase of the wastewater treatment

94 plant was not included in this assessment because they were assumed to be equal across all

95 scenarios, thus negating the contributions of these phases to the environmental assessment.

96 Scenario BwwT,03 is a hypothetical scenario which included combined collection of urine, feces,

97 and greywater, and biological treatment at the UF Water Reclamation Facility upgraded with an

98 ozonation process for pharmaceutical destruction (Ternes et al., 2003). The construction phase

99 for the ozone contactor and operational phase of the ozone process were included in this

100 assessment. Decommission of the ozone system was not taken into consideration. It was assumed

101 that no nutrients were recovered for reuse as fertilizer in Awwt and BwwT,03. Land application of

102 biosolids was excluded from the system boundary because the local utility ceased land

103 application and currently disposes of biosolids in a landfill. Furthermore, the effect that urine

104 source separation has on the composition of biosolids at the centralized wastewater treatment

105 plant is unknown. Modeling the composition of biosolids at the wastewater treatment plant after

106 urine source separation was considered outside the scope of this model.

107 Scenarios C-H were the hypothetical urine source separation scenarios. The system

108 boundary includes the processes related to potable water production, urine source separation, and

109 treatment (i.e., storage disinfection, pharmaceutical removal by ion-exchange, and struvite

110 precipitation), centralized wastewater treatment, and wastewater discharge to surface water and

111 landscape irrigation. For scenarios $\mathbf{C}_{\text {truck,landfill }}$ and $\mathbf{D}_{\text {truck,regen, }}$ urine was collected by a vacuum

112 truck and transported to a central location for processing. In scenarios $\mathbf{E}_{\text {sewer,landfill }}$ and

113 F $_{\text {sewer,regen, }}$ urine was conveyed by vacuum sewer to a central location for processing. In

114 scenarios $\mathbf{G}_{\mathbf{d e c e n}, l a n d f i l l}$ and $\mathbf{H}_{\mathbf{d e c e n}, \mathbf{r e g e n}}$, urine was collected and processed at the building level for 
115 decentralized treatment. For scenarios $\mathrm{C}_{\text {truck,landfill, }} \mathrm{E}_{\text {sewer,landfill, and }} \mathrm{G}_{\text {decen,landfill, }}$ it was assumed

116 spent anion exchange resin (AER) was transported and disposed of in a landfill. For scenarios

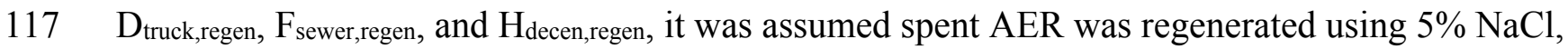

$11850 \%$ methanol, and the brine was transported and incinerated at a cement kiln plant for energy

119 recovery. The system boundaries do not include redistribution of struvite to agriculture. It was

120 assumed that struvite fertilizer would replace commercial fertilizers used in Awwt and BwwT,O3

121 and that struvite fertilizer granules were comparable to commercial fertilizers, allowing the use

122 of commercial fertilizer spreading equipment (Forrest et al., 2008). Furthermore, the ammonia,

123 nitrous oxide, and phosphate emissions for struvite and commercial fertilizer (i.e.,

124 monoammonium phosphate (MAP)) were assumed to be equivalent due to identical emission

125 factors and nutrient content (Nemecek and Kägi, 2007). However, the cadmium content of

126 struvite and commercial fertilizers were considered an emission to land (i.e., $0.39 \mathrm{mg} \mathrm{Cd} / \mathrm{kg} \mathrm{P}_{2} \mathrm{O}_{5}$

127 in struvite and $97.5 \mathrm{mg} \mathrm{Cd} / \mathrm{kgP}_{2} \mathrm{O}_{5}$ in MAP) (Lugon-Moulin et al., 2006, Ronteltap et al., 2007).

128 Infrastructure for the urine source separation system (e.g., vacuum sewer, urine piping, and ion-

129 exchange system) and operation (e.g., road transport, energy and chemical requirements) were

130 included within the system boundary. Decommission of the urine diversion and treatment system

131 was not taken into consideration.

132 2.2. Life cycle inventory

133 The data sources and design parameters used to develop foreground processes for each treatment

134 scenario are provided in detail in the SM1 (section S2). The life cycle inventory included potable

135 flush water production (section S2.1), centralized wastewater treatment (section S2.2), ozonation

136 of wastewater (section S2.3), urine source separation infrastructure (section S2.4), urine

137 collection by vacuum truck (section S2.5) or vacuum sewer (section S2.6), ion-exchange 
138 infrastructure and treatment (section S2.7), struvite precipitation for nutrient recovery (section

139 S2.8), and estimated pharmaceutical concentrations in urine (section S2.9). Background

140 inventory data for each scenario were designed using existing components in two databases, the

141 Ecoinvent unit processes (version 2.2) and the U.S. Life Cycle Inventory Database (USLCI)

142 (Ecoinvent Centre, 2015, NREL, 2012). Data from the Ecoinvent database is based on either

143 European, Swiss, or North American technologies published between 2007-2009. Data from the

144 USLCI database is based on North American technologies or processes published between 2003-

145 2008. European based data was adopted without any modification for this study.

\section{2.3. Life cycle costing}

147 The economic analysis included infrastructure and operational costs for pharmaceutical removal

148 in urine by the alternative treatment scenarios. Net present value (NPV) was estimated using an

149 interest rate of 3\% (National Center for Environmental Economics, 2010). The sources and

150 assumptions underlying all cost estimates are given in the relevant life cycle inventory sections

151 in SM1 (section S2) and are listed in Table S9 (SM1, section S4). All infrastructure costs were

152 updated to 2016 based on inflation. Labor costs were excluded in the cost analysis.

\section{2.4. Life cycle impact assessment}

154 The LCA model for all scenarios was constructed using SimaPro 8.0.3.14 software (PRé

155 Consultants, 2014). The TRACI impact assessment method was used to evaluate the

156 contributions of processes, generated, and avoided impacts to ten midpoint impact categories

157 (U.S. EPA, 2014). This method was selected because the study pertains to wastewater treatment

158 in a U.S. community and TRACI was developed by the U.S. Environmental Protection Agency.

159 The ten midpoint impact categories (e.g., ozone depletion, global warming, smog, etc.) were

160 evaluated with respect to a reference unit (e.g., $\mathrm{kg} \mathrm{CFC}-11$ eq, $\mathrm{kg} \mathrm{CO}_{2}$ eq, $\mathrm{kg} \mathrm{O} \mathrm{O}_{3}$ eq, etc.) and 
161 normalized to obtain a single impact score, expressed in Person-Equivalent (PE). Normalization

162 is a conversion step that compares the magnitude of impacts relative to a common reference. For

163 TRACI 2.1, results were normalized to the average annual impact of a U.S. citizen using 2008 as

164 the reference year (Ryberg et al., 2014).

165 The UNEP-SETAC toxicity model USEtox is the basis for the TRACI impact categories

166 for human health non-carcinogenic, and ecotoxicity and are expressed in comparative toxic units

167 (U.S. EPA, 2014). Non-carcinogenic human toxicity (CTUh) is characterized by the estimated

168 morbidity increase in the total population per unit mass of emitted chemical (disease cases $\cdot \mathrm{kg}^{-1}$ )

169 and ecotoxicity (CTUe) is an estimate of the potentially affected fraction of species over time

170 and volume per unit mass of chemical emitted $\left(\mathrm{PAF} \cdot \mathrm{m}^{3} \cdot \mathrm{day} \cdot \mathrm{kg}^{-1}\right)$. Characterization factors for

171 DCF, IBP, and NPX were obtained from literature (Alfonsín et al., 2014). The USEtox model

172 was used to determine an ecotoxicity characterization factor for KTP using the model's

173 substance database and ecotoxicity data from literature (Andersson et al., 2007, Hauschild et al.,

1742015 , Morais, 2014). A characterization factor for human toxicity was not determined for KTP

175 due to a lack of data. The characterization factors are listed in Table S10 (SM1, section S5).

\section{2.5. Sensitivity and uncertainty analysis}

177 The uncertainty of input parameters on the impact assessment results for each scenario was

178 evaluated using the integrated Monte Carlo module in SimaPro. In each Monte Carlo analysis,

1793000 iterations were conducted. Table S11 (SM1, section S6) lists all of the input parameters,

180 range of variation, justification and assumed distribution considered in the uncertainty analyses.

181 Variability of unit costs were also included to evaluate the uncertainty of assumed input

182 operational costs (SM1, section S6, Table S12). Cost variability of magnesium oxide and liquid

183 oxygen were excluded due to a lack of data. Infrastructure costs were assumed to remain 
184 constant. Additional sensitivity analyses were conducted to evaluate the effect of assumed model

185 inputs (Table S11) and unit costs (Table S12) on the environmental impacts for each scenario.

186 The sensitivity analysis was conducted by varying each parameter individually between the

187 minimum and maximum values. A parameter was considered sensitive if results varied from the

188 baseline $\pm 10 \%$.

189 3. Results and discussion

190 3.1. Overall comparison of scenarios

191 Figure 2 provides a comparison of the environmental impacts of the treatment scenarios,

192 subdivided into the contributing processes (e.g., potable water, WWTP electricity, urine

193 transport, etc.), generated impacts (e.g., nutrient and pharmaceutical emissions), and avoided

194 impacts (e.g., fertilizer offsets). Alternatively, Figure S5 (SM1, section S7) shows the same total

195 impact score of each scenario subdivided into the contributing mid-point impact categories.

196 Together, these two figures provide a holistic view of the major contributing processes and

197 impact categories to the total environmental impact. Non-normalized results for individual

198 TRACI impact categories, excluding ecotoxicity and non-carcinogenic impacts are provided in

199 SM1 (section S7, Figures S6-S13).

200 The order of decreasing total environmental impact was BwwT,03 $>$ AwwT $>E_{\text {sewer,landfill }}>$

$201 \quad F_{\text {sewer,regen }}>\mathrm{C}_{\text {truck,landfill }}>\mathrm{G}_{\text {decen,landfill }}>\mathrm{D}_{\text {truck,regen }}>\mathrm{H}_{\text {decen,regen. The trend suggests that centralized }}$

202 wastewater treatment had greater environmental impacts than the source separation scenarios,

203 primarily due to the potable water requirements for flushing, electricity for wastewater treatment,

204 and nutrient emissions. Furthermore, struvite precipitation of source separated urine reduces

205 nutrient emissions, offsets commercial fertilizer production, and reduces cadmium emissions due

206 to commercial fertilizers. These results are similar to other LCA studies that found that potable 
207 water savings, electricity savings, reduction in nutrient loading, and reduced cadmium emissions

208 from commercial fertilizers in the environment are major benefits gained from urine source

209 separation (Berndtsson, 2006, Ishii and Boyer, 2015, Lam et al., 2015, Lamichhane and

210 Babcock, 2012, Ronteltap et al., 2007). Results of the Monte Carlo simulation indicate that

211 uncertainty does not affect the overall trends for the total environmental impact, where AwwT

212 and BwwT,O3 have greater observed environmental impact compared with the urine source

213 separation and the vacuum sewer scenarios had the largest impact among the source separation

214 scenarios. However, there was uncertainty between scenarios $C_{\text {truck,landfill, }} \mathrm{D}_{\text {truck,regen, }} \mathrm{G}_{\text {decen,landfill, }}$

215 and $H_{\text {decen,regen }}$ at the $97.5 \%$ confidence interval suggesting that the difference in environmental

216 impact of urine collection by vacuum truck or decentralized treatment is not significant.

217 However, the total environmental impact for the resin disposal scenarios was less than the

218 scenarios where resin was disposed of in a landfill (e.g., $C_{\text {truck,landfill }}>D_{\text {truck,regen). Within impact }}$

219 categories, Awwt and Bwwt,03 maintained the greatest impact for all categories except ozone

220 depletion. However, some uncertainty was observed within impact categories for the source

221 separation scenarios, with the exception of the eutrophication impact category.

222 Replacing conventional fixtures with urine diverting flush toilets and waterless urinals

223 would conserve $2.6 \times 10^{5} \mathrm{~m}^{3}$ of potable flush water and $\$ 231,000$ annual potable water savings.

224 The implications of potable water savings would be of particular importance in areas that face

225 water scarcity and quality issues (Ishii and Boyer, 2015). Accounting for the reduction in potable

226 flush water, influent flow at the wastewater treatment plant would decrease by $17 \%$. This

227 reduction in influent flow could reduce the electricity requirements for wastewater treatment. A

228 limitation of this study is that quantifying electricity use at the plant simplifies the impact urine

229 source separation can have on centralized wastewater treatment. Jimenez et al. (2015) found that 
230 urine source separation can reduce influent $\mathrm{N}$ and $\mathrm{P}$ loading and potentially eliminate the need

231 for nitrification, reduce sludge age, and reduce chemical requirements for chemical P removal.

232 Table 1 provides a summary of the estimated economic impacts associated with

233 infrastructure, energy, potable flush water, chemicals, and urine-based fertilizer revenue for each

234 treatment scenario. The NPV and EAC of scenarios $\mathrm{C}_{\text {truck,landfill, }} \mathrm{D}_{\text {truck,regen, }}, \mathrm{G}_{\text {decen,landfill, and }}$

$235 \mathrm{H}_{\text {decen,regen }}$ vary from Awwt by only $\pm 2-13 \%$. These scenarios could be considered comparable to

236 Awwt due to the preliminary nature and uncertainty of the economic evaluation. However, the

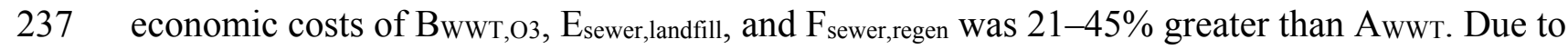

238 the uncertainty of the input parameters and unit costs, Monte Carlo analysis show that the cost of

239 each scenario increases and decreases at the $2.5 \%$ confidence interval (CI) and 97.5\% CI,

240 respectively. Compared across scenarios, cost savings for urine source separation may be even

241 greater (i.e., $48 \%-69 \%$ less than Awwt) at the 2.5\% confidence interval (CI). However, at the

$24297.5 \%$ CI, observed trends were the same as the baseline values. This suggests that scenarios

$243 \mathrm{C}_{\text {truck,landfill, }} \mathrm{D}_{\text {truck,regen, }} \mathrm{G}_{\text {dececn,landfill, and }} \mathrm{H}_{\text {decen,regen have lower environmental impact and similar or }}$

244 lower economic cost compared to Awwt. This result is similar to Ishii and Boyer (2015) which

245 concluded that urine source separation and struvite precipitation for maximum P recovery had

246 significantly lower environmental impact but negligible cost differences, compared with

247 centralized wastewater treatment. This suggests that the cost of additional pharmaceutical

248 treatment of source separated urine would not limit implementation.

\section{3.2. Urine source separation}

250 The urine source separation scenarios had a lower impact for all impact categories compared

251 with Awwt and Bwwt,03, with the exception of the ozone depletion impact category (Figure 2).

252 Anion exchange resin is the major contributing process to the ozone depletion impact category 
253 because of the trichloromethane solvent used to add quaternary amine functional groups to the 254 polymer backbone for a type I AER (SM1, section S7, Figure S6) (Althaus et al., 2007). This 255 result differs from Choe et al. (2013) who found that ion-exchange resins dominate all impact 256 categories except for ozone depletion, however ion-exchange resin was modeled as a general 257 polystyrene and did not include the additional functionalization step in resin manufacturing.

258 Eutrophication is the greatest contributor to the total environmental impact in the source 259 separation scenarios, which is primarily due to the $\mathrm{N}$ remaining in urine after struvite 260 precipitation for P recovery (SM1, section S7, Figure S5 and Figure S10). However, Ishii and 261 Boyer (2015) found that struvite precipitation for maximum $\mathrm{P}$ and $\mathrm{N}$ recovery had a greater 262 environmental impact than struvite precipitation for maximum P recovery due to the chemical 263 inputs. This suggests that alternative $\mathrm{N}$ removal or recovery technologies should be explored. 264 Alternatively, direct application of stored liquid urine could serve as a complete nutrient source 265 (Kirchmann and Pettersson, 1995), with the added benefit of reducing both $\mathrm{N}$ and P loading at 266 the wastewater treatment plant and subsequent receiving waters. Coupled with the fact that $\mathrm{MgO}$ 267 and struvite storage requirements had the second greatest environmental impact in $\mathrm{C}_{\text {truck,landfill, }}$ $268 D_{\text {truck,regen, }} G_{\text {dececn,landfill, }}$ and $H_{\text {decen,regen, application of liquid urine may reduce the total }}$ 269 environmental impact. However, the social implications of applying liquid urine compared to a 270 urine-derived solid fertilizer should be considered. In general, user acceptance surveys found that $271>79 \%$ of respondents approved from urine source separation technology in residence halls, 272 public buildings, or workplaces (Ishii and Boyer, 2016, Lienert and Larsen, 2010), and 85\% 273 approved of urine-derived fertilizers (Lienert and Larsen, 2010). However, only $50 \%$ of farmers 274 regarded urine fertilizer as a good idea primarily due to fear of liability (Lienert and Larsen, 275 2010). Farmers in Switzerland preferred a grainy and odorless ammonium nitrate fertilizer, but 
276 they were willing to use odorous urine fertilizer in fields (Lienert et al., 2003). This suggests that

277 a mineral fertilizer (e.g., struvite) may be more appropriate for application in urban areas

278 compared with liquid urine, which could be applied in rural and agricultural settings.

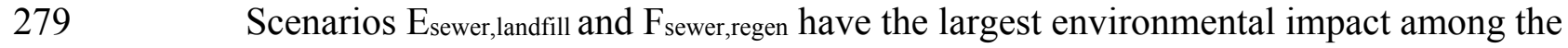

280 source separation scenarios due to the vacuum sewer infrastructure and operation. This indicates

281 that the method of urine collection and handling (e.g., vacuum sewer vs. vacuum truck vs.

282 decentralized treatment) is a critical consideration during the design phase. The material and

283 process inputs for the vacuum sewer system is largely dependent on the geographical size of the

284 collection area. Conversely, the process inputs for collection by vacuum truck is dependent on

285 both distance traveled (size of collection area) and volume of urine produced. As shown in

286 Figure S15, the total normalized impact of the vacuum sewer exceeds vacuum truck collection

287 when plotted as a function of total pipe length of the sewer system or distance traveled $(\mathrm{km})$.

288 This suggests that a vacuum sewer system would have a greater environmental impact than

289 vacuum truck collection, regardless of the size of the collection area. Overall, centralized urine

290 treatment collected by vacuum truck and decentralized urine treatment had the lowest

291 environmental impact. However, the feasibility of implementing multiple decentralized systems

292 on a large scale must be considered. Facilities and maintenance staff maintain all building

293 services and operations (e.g., janitorial and maintenance) on campus. It is expected that

294 maintenance staff would maintain the ion-exchange system and struvite precipitation operations.

295 This would be a significant new task for maintenance staff to undertake and would likely require

296 hiring personnel to handle these tasks or subcontracting to a private firm. The labor requirements

297 and additional costs were not included in this model but could be considered in future work

298 (Ramos et al., 2014). With respect to other types of communities, decentralized treatment may be 
more appropriate in rural areas. For example, Wood et al. (2015) found that urine diversion

300 coupled with conventional septic systems for greywater management exhibited the lowest

301 economic cost and highest cost effectiveness for $\mathrm{N}$ mitigation for rural households.

302 The scenarios where spent resin was disposed of in a landfill had a slightly greater

303 environmental impact than the scenarios where resin was regenerated and the waste regeneration

304 solution (i.e., $5 \% \mathrm{NaCl}, 50 \%$ methanol) was incinerated at a cement kiln plant. Although the

305 production of methanol, salt, and potable water used for regeneration generates environmental

306 impact, greater environmental offsets were achieved from incinerating the methanol-containing

307 brine for energy recovery as opposed to fossil fuels used at the cement kiln plant (SM1, section

308 S8, Figure S14). A limitation of the Ecosolvent model used to generate the life cycle inventory

309 for brine incineration is that it represents Swiss technology, however plants may vary according

310 to the kiln and flue gas treatment technology (Seyler et al., 2005). Furthermore, the fuel mix

311 assumed in the Ecosolvent model is different compared to the U.S. cement kiln industry (Hanle,

312 2004). Choe et al. (2013) and Maul et al. (2014) found that salt requirements for the ion-

313 exchange was the major contributor to the environmental impact of an ion-exchange process.

314 This indicates that improving the sustainability of ion-exchange regeneration (e.g., brine

315 incineration for energy recovery or brine recycling) can make regeneration more favorable than

316 disposing of resin in a landfill. The potential benefits from incinerating the regeneration brine are

317 two-fold: environmental offsets due to reduced fossil fuel consumption and ultimate destruction

318 of the pharmaceuticals to prevent release to the environment. An additional driver for resin

319 regeneration and brine incineration, as opposed to landfill disposal, is the potential for

320 pharmaceuticals to end up in landfill leachate (Lu et al., in press). However, occurrence of

321 pharmaceuticals in landfill leachate was not included within the LCA framework. Alternatively, 
322 a semi-closed loop system may be developed by destroying pharmaceuticals in the regeneration

323 brine by advanced oxidation processes to allow brine recycling (Zhang et al., 2015).

\section{3.3. Pharmaceutical toxicity}

325 Figure 3a shows the TRACI impact results for ecotoxicity $\left(\mathrm{CTU}_{\mathrm{e}}\right)$ subdivided into the 326 contributing processes, generated impacts, and avoided impact, and Figure $3 \mathrm{~b}$ shows the

327 ecotoxicity impact only due to pharmaceutical emissions in wastewater effluent discharged to 328 surface water and reclaimed water. A similar figure for non-carcinogenic human toxicity $\left(\mathrm{CTU}_{\mathrm{h}}\right)$ 329 is given in SM1 (section S10, Figure S16). For brevity, this discussion focuses on ecotoxicity

330 because the same general trends were observed for human toxicity. Overall, the order of

331 decreasing total ecotoxicity was $\mathrm{BwwT,03}_{\mathrm{W}}>\mathrm{AwwT}_{\mathrm{w}}>\mathrm{E}_{\text {sewer,landfill }}>\mathrm{F}_{\text {sewer,regen }}>\mathrm{C}_{\text {truck,landfill }}>$

$332 \mathrm{G}_{\text {decen,landfill }}>\mathrm{D}_{\text {truck,regen }}>\mathrm{H}_{\text {decen,regen }}$ (Figure 3a). Ecotoxicity due to pharmaceutical emissions

333 followed a decreasing trend of $\mathrm{AwwT}_{\mathrm{w}}>\mathrm{C}_{\text {truck,landfill }}=\mathrm{D}_{\text {truck,regen }}=\mathrm{E}_{\text {sewer,landfill }}=\mathrm{F}_{\text {sewer, regen }}=$

$334 \mathrm{G}_{\mathrm{decen}, \text { landfill }}=\mathrm{H}_{\text {decen,regen }}>\mathrm{B}_{\mathrm{wwT}, \mathrm{O} 3}($ Figure $3 \mathrm{~b})$.

335 As expected, Awwt had the greatest ecotoxicity due to pharmaceutical emissions because 336 biological treatment only achieves $28-87 \%$ pharmaceutical removal and can vary for individual 337 pharmaceuticals (Fernandez-Fontaina et al., 2012, Hollender et al., 2009, Joss et al., 2005,

338 Lindqvist et al., 2005, Rivera-Utrilla et al., 2013, Rosal et al., 2010, Salgado et al., 2012, Ternes, 339 1998). The fate of pharmaceuticals in raw wastewater is removal by adsorption to sludge and/or 340 biotransformation, or discharged in the effluent (Cook et al., 2012). Furthermore, biological 341 wastewater treatment does not maintain consistent treatment efficiencies as observed by negative 342 mass balances in wastewater effluent (Blair et al., 2015). Although biosolids disposal was not 343 included within the framework of the LCA, land application of biosolids is a common emission 344 source for pharmaceuticals in wastewater treatment. It was estimated that 210-250 tonnes year ${ }^{-1}$ 
345 of 72 pharmaceuticals and personal care products are land applied to U.S. soils from biosolids 346 recycling, nationwide (McClellan and Halden, 2010). The pharmaceuticals investigated in this

347 study, on average, were estimated to be removed 5-7\% by sludge adsorption based on their 348 sludge adsorption coefficient $\left(\mathrm{K}_{\mathrm{d}}\right)$ (Alvarino et al., 2014, Blair et al., 2015, Carballa et al., 2008, 349 Jelic et al., 2011, Jones et al., 2002, Joss et al., 2005, Radjenović et al., 2009, Sipma et al., 2010).

350 High variability of overall removal suggests that biological wastewater treatment cannot 351 consistently achieve effective removal of pharmaceuticals.

352 Scenario Bwwт,oz had the lowest pharmaceutical ecotoxicity due to high pharmaceutical 353 destruction (53-98\%) (Hollender et al., 2009, Margot et al., 2013, Rosal et al., 2010, Ternes et 354 al., 2003), however it exhibits the greatest total ecotoxicity due to the additional ozone process 355 (e.g., ozone contactor infrastructure, electricity, liquid oxygen, water, and transport 356 requirements). One of the limitations of this model is that only the ecotoxicity of the parent 357 compound is considered and reduction in ecotoxicity is directly related to its removal. However, 358 ecotoxicity studies have shown that more toxic byproducts may be formed after ozonated 359 wastewater compared to the pre-ozonated water and would require an extended contact time, or 360 an additional treatment step such as sand filtration or activated carbon, to remove the oxidation 361 byproduct (Magdeburg et al., 2012, Sánchez-Polo et al., 2008, Stalter et al., 2010).

362 For the urine source separation scenarios, the total ecotoxicity impact is $90 \%$ less than 363 Awwт and Bwwт,03, primarily due to the reduction in potable water use and electricity at the 364 wastewater treatment plant (Figure 3a). Indirect toxicity of producing auxiliary materials and 365 energy for potable water production and electricity use at the wastewater treatment plant is 366 originated by several substances emitted to water during electricity production and lime sludge 367 disposal (for potable water production only). As shown in Figure 3b, the toxicity due to 
368 pharmaceutical emissions is the same for all urine source separation scenarios because equivalent

369 pharmaceutical removal was achieved by ion-exchange. In general, pharmaceutical ecotoxicity

370 followed a decreasing order of IBP $>$ DCF $>$ KTP $>$ NPX. The fact that DCF removal was

371 highest in these treatment scenarios (98\% removal) but remains the second most toxic

372 pharmaceutical highlights the importance of evaluating the reduction in toxicity of each

373 pharmaceutical as opposed to the average mass removal. Considering the majority of

374 pharmaceuticals in centralized wastewater come from human urine, separation and treatment of

375 this unique waste stream may be the most effective pharmaceutical management strategy. An

376 expressed limitation of LCA regarding toxicity include not being able to accurately evaluate

377 mixture toxicity (Muñoz et al., 2009). Toxicity studies have observed antagonistic or synergistic

378 toxicity effects in pharmaceutical mixtures (Pomati et al., 2008). However, a recent study by

379 Watanabe et al. (2015) found that concentration addition and independent action are accurate at

380 predicting chronic mixture toxicity of pharmaceuticals at environmentally relevant

381 concentrations. In addition, LCA does not evaluate endocrine disruption potential due to limited

382 information and lack of an epidemiological framework (Finkbeiner et al., 2014). Another

383 limitation of this model is that the pharmaceuticals evaluated in this study (i.e., non-steroidal

384 anti-inflammatory drugs) are not comprehensive of all pharmaceutical compounds with respect

385 to toxicity and removal efficiency.

386 3.4. Model sensitivity

387 Supplementary Material 2 (SM2) show the results of the sensitivity analysis as a percent change

388 in each urine treatment scenario's impact within an impact category, total impact, and total cost,

389 relative to the baseline assumption; impact changes within varying ranges (i.e., 10-19\%, 20

$39049 \%$, and $\geq 50 \%$ ) are highlighted in color. Overall, the most sensitive assumptions to the model 
391 were pharmaceutical concentrations in urine, TN and TP in urine, WWTP energy, storage time,

392 and resin capacity. Similar to Ishii and Boyer (2015), the various impact categories within the

393 treatment scenarios were sensitive to the assumed concentration of $\mathrm{P}$ in urine, the assumption for

394 electricity use at the wastewater treatment plant, and storage time. In general, Awwt and Bwwt,O3

395 maintained the greatest total impact throughout the entire sensitivity analysis. Although the

396 model was sensitive to the assumed WWTP energy requirements, and TN and TP concentrations

397 in urine, the observed trend for total environmental impact for the scenarios remained the same.

398 The source separation scenarios were sensitive to the assumed pharmaceutical

399 concentrations in urine for three out of ten impact categories (i.e., ozone depletion, acidification,

400 and respiratory effects). A decrease or increase in impact was observed when pharmaceutical

401 concentrations were minimized or maximized, respectively. This was attributed to the decrease

402 or increase in resin and chemical requirements (i.e., $\mathrm{NaCl}$ and methanol for regeneration), and

403 size of the ion-exchange vessel. An inverse relationship (e.g., a decrease in impact when

404 pharmaceutical concentrations were maximized) was observed for $\mathrm{D}_{\text {truck,regen, }} \mathrm{F}_{\text {sewer,regen, and }}$

$405 \mathrm{H}_{\text {decen,regen. This was due to the greater methanol requirements for regeneration and subsequent }}$

406 fossil fuel offsets due to brine incineration at the cement kiln plant. Uncertainty regarding the

407 estimated pharmaceutical concentrations in urine may be improved with increased sampling

408 campaigns, improved understanding of pharmaceutical consumption, and modeling procedures.

409 A model developed by Winker et al. (2008b) to predict pharmaceutical concentrations in urine

410 had a strong correlation but only accounted for prescribed pharmaceuticals, however a

411 significant amount of pharmaceuticals may be purchased over-the-counter. Furthermore, there is

412 a lack of data regarding the amount of over-the-counter pharmaceuticals actually consumed. A

413 similar trend was observed when the column was sized to achieve maximum IBP removal 
414 compared to the baseline, which was sized to achieve maximum DCF removal. Due to the low

415 capacity of the AER for IBP compared to DCF resin, chemical requirements and corresponding

416 fossil fuel offsets from brine incineration increased, resulting in a decrease in impact for the

417 regeneration scenarios, increase in impact for the landfill scenarios, and an increase in total cost.

418 The results of the economic sensitivity analysis are shown in SM2. Table S2.2 (SM2,

419 section S2) shows the percent change from the baseline NPV values for each scenario,

420 respectively. Table S2.3 (SM2, section S2) shows the percent difference in NPV compared with

421 Scenario A. The cost of urine diverting flush toilets and waterless urinals was the most sensitive

422 cost for the urine source separation scenario and also the largest single economic cost. Urine-

423 diverting flush toilets are not widely used compared with conventional toilets. Considering the

424 material inputs of these fixtures do not differ from conventional toilets, it is reasonable to expect

425 that increasing demand would decrease market price. If market value of these fixtures cost the

426 same as conventional fixtures, urine source separation would cost $18-54 \%$ less than Awwt. Total

427 cost was also sensitive to utility rates for potable water and electricity, particularly for AwwT and

428 Bwwt,03. For example, when the cost of potable water was minimized, the cost of urine source

429 separation was 24-75\% greater than Awwt. However, when the cost was maximized, urine

430 source separation cost 63-74\% less than Awwt. A similar trend was observed for electricity

431 costs. This suggests that potable water or electricity savings may be a driver for or against

432 implementation of urine source separation, depending on the community. Finally, the total cost

433 was sensitive to the assumed interest rate. In general, as interest rate increased, the cost of

434 Bwwt,O3 increased compared to Awwt, and the cost of urine source separation decreased

435 compared to Awwt.

436 4. Conclusions 
437 There are numerous environmental benefits associated with urine source separation (e.g., potable

438 flush water savings, electricity savings at the wastewater treatment plant, and nutrient offsets),

439 Compared with centralized wastewater treatment, ozonation of wastewater had a higher

440 environmental impact and economic cost, urine collected by vacuum sewer had lower

441 environmental impact and higher economic cost, and urine collected by vacuum truck collection

442 or treated at decentralized locations had lower environmental impact and similar economic cost.

443 Urine source separation can achieve a high reduction of pharmaceutical toxicity and

444 comparatively low total toxicity from the treatment process compared with BwwT,03. Additional

445 sorption studies are needed to evaluate the removal of various pharmaceutical compounds from

446 diverse therapeutic classes and chemical structure, the results of which could be incorporated

447 into a future version of this LCA framework. The benefit of this LCA framework is that the

448 environmental impact and economic cost of alternative sorbents can easily be evaluated.

449 Although the AER used for this study may not be the most appropriate to remove all

450 pharmaceuticals, multiple sorbents may be utilized which have a higher selectivity and capacity

451 for the pharmaceuticals of concern. Using a more selective and higher capacity resin would

452 decrease the resin requirements and subsequent costs. In conclusion, the framework created and

453 tested herein estimates the environmental and economic impacts of alternative treatment

454 technologies that remove pharmaceuticals and recover nutrients in source separated urine in a

455 community setting.

\section{Acknowledgements}

457 The authors would like to thank Dr. Guenther Hochhaus at the University of Florida for his 458 assistance with sample analysis, the UF Physical Plant Department, and UF Water Reclamation 459 Facility. This material is based upon work supported by the National Science Foundation 
461 CBET-1150790. This article was greatly improved by the thoughts and insightful comments

462 from two anonymous reviewers. Any opinions, findings, conclusions or recommendations

463 expressed in this publication are those of the authors and do not necessarily reflect the views of

464 NSF. KAL also received support from the FSAWWA Roy W. Likins Scholarship.

465 References

466 Alfonsín, C., Hospido, A., Omil, F., Moreira, M.T. and Feijoo, G. (2014) PPCPs in wastewater 467 Update and calculation of characterization factors for their inclusion in LCA studies. Journal of 468 Cleaner Production 83, 245-255.

469 Althaus, H.J., Hischier, R. and Osses, M. (2007) Life Cycle Inventories of Chemicals, Data v2.0.

470 Alvarino, T., Suarez, S., Lema, J.M. and Omil, F. (2014) Understanding the removal

471 mechanisms of PPCPs and the influence of main technological parameters in anaerobic UASB

472 and aerobic CAS reactors. Journal of Hazardous Materials 278, 506-513. Andersson, J., EKHEDEN, Y., KAJ, L., REMBERGER, M. and WOLDEGIORGIS, A. (2007) Results from the Swedish National Screening Programme, 2005. Subreport 1: Antibiotics, AntiInflammatory Substances, and Hormones.

Berndtsson, J.C. (2006) Experiences from the implementation of a urine separation system: Goals, planning, reality. Building and Environment 41(4), 427-437.

Blair, B., Nikolaus, A., Hedman, C., Klaper, R. and Grundl, T. (2015) Evaluating the degradation, sorption, and negative mass balances of pharmaceuticals and personal care products during wastewater treatment. Chemosphere 134, 395-401.

Carballa, M., Fink, G., Omil, F., Lema, J.M. and Ternes, T. (2008) Determination of the solidwater distribution coefficient $(\mathrm{Kd})$ for pharmaceuticals, estrogens and musk fragrances in digested sludge. Water Research 42(1-2), 287-295.

Choe, J.K., Mehnert, M.H., Guest, J.S., Strathmann, T.J. and Werth, C.J. (2013) Comparative Assessment of the Environmental Sustainability of Existing and Emerging Perchlorate Treatment Technologies for Drinking Water. Environmental Science \& Technology 47(9), 4644-4652. Cook, S.M., VanDuinen, B.J., Love, N.G. and Skerlos, S.J. (2012) Life Cycle Comparison of Environmental Emissions from Three Disposal Options for Unused Pharmaceuticals.

Environmental Science \& Technology 46(10), 5535-5541.

Crittenden, J.C., Trussell, R.R., Hand, D.W., Howe, K.J. and Tchobanoglous, G. (2012) MWH's Water Treatment: Principles and Design. Ecoinvent Centre (2015), http://www.ecoinvent.org/database/database.html Fernandez-Fontaina, E., Omil, F., Lema, J.M. and Carballa, M. (2012) Influence of nitrifying conditions on the biodegradation and sorption of emerging micropollutants. Water Research 46(16), 5434-5444.

Finkbeiner, M., Ackermann, R., Bach, V., Berger, M., Brankatschk, G., Chang, Y.-J., Grinberg, M., Lehmann, A., Martínez-Blanco, J., Minkov, N., Neugebauer, S., Scheumann, R., Schneider, 498 L. and Wolf, K. (2014) Background and Future Prospects in Life Cycle Assessment. Klöpffer, 499 W. (ed), pp. 207-258, Springer Netherlands, Dordrecht. 

Phosphate Recovery in WWTP. Journal of Environmental Engineering 134(5), 395-402. Hanle, L.J. (2004), $\mathrm{CO}_{2}$ emissions profile of the U.S. cement industry. Washington D.C., 2004. https://www3.epa.gov/ttnchie1/conference/ei13/ghg/hanle.pdf Hauschild, M., McKone, T., Van de Meent, D., Huijbregts, M., Margni, M., Rosenbaum, R.K., Jolliet, O. and Fantke, P., USEtox 2.0 (2015). Hernando, M.D., Mezcua, M., Fernández-Alba, A.R. and Barceló, D. (2006) Environmental risk assessment of pharmaceutical residues in wastewater effluents, surface waters and sediments. Talanta 69(2), 334-342.

Hollender, J., Zimmermann, S., Koepke, S., Krauss, M., McArdell, C., Ort, C., Singer, H., von Gunten, U. and Siegrist, H. (2009) Elimination of Organic Micropollutants in a Municipal Wastewater Treatment Plant Upgraded with a Full-Scale Post-Ozonation Followed by Sand Filtration. Environmental Science \& Technology 43(20), 7862-7869. Igos, E., Benetto, E., Venditti, S., Kohler, C. and Cornelissen, A. (2013) Comparative and integrative environmental assessment of advanced wastewater treatment processes based on an average removal of pharmaceuticals. Water Science and Technology 67(2). Igos, E., Benetto, E., Venditti, S., Kohler, C., Cornelissen, A., Moeller, R. and Biwer, A. (2012) Is it better to remove pharmaceuticals in decentralized or conventional wastewater treatment plants? A life cycle assessment comparison. Science of The Total Environment 438(0), 533-540. Ishii, S.K.L. and Boyer, T.H. (2015) Life cycle comparison of centralized wastewater treatment and urine source separation with struvite precipitation: Focus on urine nutrient management. Water Research 79, 88-103. Ishii, S.K.L. and Boyer, T.H. (2016) Student support and perceptions of urine source separation in a university community. Water Research 100, 146-156. Jelic, A., Gros, M., Ginebreda, A., Cespedes-Sánchez, R., Ventura, F., Petrovic, M. and Barcelo, D. (2011) Occurrence, partition and removal of pharmaceuticals in sewage water and sludge during wastewater treatment. Water Research 45(3), 1165-1176. Jimenez, J., Bott, C., Love, N. and Bratby, J. (2015) Source Separation of Urine as an Alternative Solution to Nutrient Management in Biological Nutrient Removal Treatment Plants. Water Environ Res 87(12), 2120-2129.

Jones, O.A.H., Voulvoulis, N. and Lester, J.N. (2002) Aquatic environmental assessment of the top 25 English prescription pharmaceuticals. Water Research 36(20), 5013-5022. Joss, A., Keller, E., Alder, A., Gobel, A., McArdell, C., Ternes, T. and Siegrist, H. (2005) Removal of pharmaceuticals and fragrances in biological wastewater treatment. Water Research 39(14), 3139-3152.

Kirchmann, H. and Pettersson, S. (1995) Human Urine - Chemical-Composition and Fertilizer Use Efficiency. Fertilizer Research 40(2), 149-154.

Lam, L., Kurisu, K. and Hanaki, K. (2015) Comparative environmental impacts of sourceseparation systems for domestic wastewater management in rural China. Journal of Cleaner Production 104, 185-198.

Lamichhane, K. and Babcock, R. (2012) An economic appraisal of using source separation of human urine to contain and treat endocrine disrupters in the USA. Journal of Environmental Monitoring 14(10), 2557-2565.

Landry, K.A. and Boyer, T.H. (2013) Diclofenac removal in urine using strong-base anion exchange polymer resins. Water Research 47(17), 6432-6444. 
Landry, K.A., Sun, P., Huang, C.-H. and Boyer, T.H. (2015) Ion-exchange selectivity of diclofenac, ibuprofen, ketoprofen, and naproxen in ureolyzed human urine. Water Research 68(0), 510-521. Larsen, T. and Gujer, W. (1996) Separate management of anthropogenic nutrient solutions (human urine). Water Science and Technology 34(3-4), 87-94.

Lienert, J., Burki, T. and Escher, B. (2007a) Reducing micropollutants with source control: substance flow analysis of 212 pharmaceuticals in faeces and urine. Water Science and Technology 56(5), 87-96.

Lienert, J., Gudel, K. and Escher, B. (2007b) Screening method for ecotoxicological hazard assessment of 42 pharmaceuticals considering human metabolism and excretory routes. Environmental Science \& Technology 41(12), 4471-4478.

Lienert, J., Haller, M., Berner, A., Stauffacher, M. and Larsen, T.A. (2003) How farmers in Switzerland perceive fertilizers from recycled anthropogenic nutrients (urine). Water Sci Technol 48(1), 47-56. Lienert, J. and Larsen, T.A. (2010) High Acceptance of Urine Source Separation in Seven European Countries: A Review. Environmental Science \& Technology 44(2), 556-566. Lindqvist, N., Tuhkanen, T. and Kronberg, L. (2005) Occurrence of acidic pharmaceuticals in raw and treated sewages and in receiving waters. Water Research 39(11), 2219-2228. Lu, M.-C., Chen, Y.Y., Chiou, M.-R., Chen, M.Y. and Fan, H.-J. (in press) Occurrence and treatment efficiency of pharmaceuticals in landfill leachates. Waste Management.

Lugon-Moulin, N., Ryan, L., Donini, P. and Rossi, L. (2006) Cadmium content of phosphate fertilizers used for tobacco production. Agron. Sustain. Dev. 26(3), 151-155. Magdeburg, A., Stalter, D. and Oehlmann, J. (2012) Whole effluent toxicity assessment at a wastewater treatment plant upgraded with a full-scale post-ozonation using aquatic key species. Chemosphere 88(8), 1008-1014.

Margot, J., Kienle, C., Magnet, A., Weil, M., Rossi, L., de Alencastro, L.F., Abegglen, C., Thonney, D., Chèvre, N., Schärer, M. and Barry, D.A. (2013) Treatment of micropollutants in municipal wastewater: Ozone or powdered activated carbon? Science of The Total Environment 461-462, 480-498.

Maul, G.A., Kim, Y., Amini, A., Zhang, Q. and Boyer, T.H. (2014) Efficiency and life cycle environmental impacts of ion-exchange regeneration using sodium, potassium, chloride, and bicarbonate salts. Chemical Engineering Journal 254(0), 198-209.

Maurer, M., Schwegler, P. and Larsen, T.A. (2003) Nutrients in urine: energetic aspects of removal and recovery. Water Science and Technology 48(1), 37-46.

McClellan, K. and Halden, R.U. (2010) Pharmaceuticals and Personal Care Products in Archived U.S. Biosolids from the 2001 EPA National Sewage Sludge Survey. Water Research 44(2), 658668.

Morais, S.A. (2014) Multimedia fate modelling and impact of pharmaceutical compounds on freshwater ecosystems.

Muñoz, I., José Gómez, M., Molina-Díaz, A., Huijbregts, M.A.J., Fernández-Alba, A.R. and García-Calvo, E. (2008) Ranking potential impacts of priority and emerging pollutants in urban wastewater through life cycle impact assessment. Chemosphere 74(1), 37-44.

Muñoz, I., Rodríguez, A., Rosal, R. and Fernández-Alba, A.R. (2009) Life Cycle Assessment of urban wastewater reuse with ozonation as tertiary treatment: A focus on toxicity-related impacts. Science of The Total Environment 407(4), 1245-1256. 
National Center for Environmental Economics (2010), Guidelines for preparing economic analyses. U.S. Environmental Protection Agency, https://yosemite.epa.gov/ee/epa/eerm.nsf/vwAN/EE-0568-50.pdf/\$file/EE-0568-50.pdf Nemecek, T. and Kägi, T. (2007) Life cycle inventories of agricultural production systems, Data v2.0, Ecoinvent Centre, Zurich and Dubendorf. NREL (2012), U.S. Life Cycle Inventory Database. https://www.lcacommons.gov/nrel/search Ort, C., Lawrence, M.G., Reungoat, J., Eaglesham, G., Carter, S. and Keller, J. (2010) Determining the fraction of pharmaceutical residues in wastewater originating from a hospital. Water Research 44(2), 605-615. Pomati, F., Orlandi, C., Clerici, M., Luciani, F. and Zuccato, E. (2008) Effects and Interactions in an Environmentally Relevant Mixture of Pharmaceuticals. Toxicological Sciences 102(1), 129-137.

PRé Consultants (2014), http://www.pre-sustainability.com/

Radjenović, J., Petrović, M. and Barceló, D. (2009) Fate and distribution of pharmaceuticals in wastewater and sewage sludge of the conventional activated sludge (CAS) and advanced membrane bioreactor (MBR) treatment. Water Research 43(3), 831-841. Ramos, T.R.P., Gomes, M.I. and Barbosa-Póvoa, A.P. (2014) Planning a sustainable reverse logistics system: Balancing costs with environmental and social concerns. Omega 48, 60-74. Remy, C. (2010) Life Cycle Assessment of conventional and source-separation systems for urban wastewater management. Ph.D. Dissertation, Technische Universität Berlin.

Rivera-Utrilla, J., Sánchez-Polo, M., Ferro-García, M.Á., Prados-Joya, G. and Ocampo-Pérez, R. (2013) Pharmaceuticals as emerging contaminants and their removal from water. A review. Chemosphere 93(7), 1268-1287.

Ronteltap, M., Maurer, M. and Gujer, W. (2007) The behaviour of pharmaceuticals and heavy metals during struvite precipitation in urine. Water Research 41(9), 1859-1868.

Rosal, R., Rodríguez, A., Perdigón-Melón, J.A., Petre, A., García-Calvo, E., Gómez, M.J., Agüera, A. and Fernández-Alba, A.R. (2010) Occurrence of emerging pollutants in urban wastewater and their removal through biological treatment followed by ozonation. Water Research 44(2), 578-588.

Ryberg, M., Vieira, M.M., Zgola, M., Bare, J. and Rosenbaum, R. (2014) Updated US and Canadian normalization factors for TRACI 2.1. Clean Technologies and Environmental Policy 16(2), 329-339.

Salgado, R., Marques, R., Noronha, J., Carvalho, G., Oehmen, A. and Reis, M. (2012) Assessing the removal of pharmaceuticals and personal care products in a full-scale activated sludge plant. Environmental Science and Pollution Research 19(5), 1818-1827.

Sánchez-Polo, M., Rivera-Utrilla, J., Prados-Joya, G., Ferro-García, M.A. and Bautista-Toledo, I. (2008) Removal of pharmaceutical compounds, nitroimidazoles, from waters by using the ozone/carbon system. Water Research 42(15), 4163-4171.

Seyler, C., Hellweg, S., Monteil, M. and Hungerbühler, K. (2005) Life Cycle Inventory for Use of Waste Solvent as Fuel Substitute in the Cement Industry - A Multi-Input Allocation Model (11 pp). The International Journal of Life Cycle Assessment 10(2), 120-130.

Sipma, J., Osuna, B., Collado, N., Monclús, H., Ferrero, G., Comas, J. and Rodriguez-Roda, I. (2010) Comparison of removal of pharmaceuticals in MBR and activated sludge systems. Desalination 250(2), 653-659. 
634 Stalter, D., Magdeburg, A., Weil, M., Knacker, T. and Oehlmann, J. (2010) Toxication or 635 detoxication? In vivo toxicity assessment of ozonation as advanced wastewater treatment with 636 the rainbow trout. Water Research 44(2), 439-448.

637 Ternes, T.A. (1998) Occurrence of drugs in German sewage treatment plants and rivers. Water 638 Research 32(11), 3245-3260.

639 Ternes, T.A., Stüber, J., Herrmann, N., McDowell, D., Ried, A., Kampmann, M. and Teiser, B. 640 (2003) Ozonation: a tool for removal of pharmaceuticals, contrast media and musk fragrances 641 from wastewater? Water Research 37(8), 1976-1982.

642 U.S. EPA (2014), Tool for the Reduction and Assessment of Chemical and Other Environmental 643 Impacts. http://www.epa.gov/nrmrl/std/traci/traci.html

644 Verlicchi, P., Al Aukidy, M. and Zambello, E. (2012) Occurrence of pharmaceutical compounds 645 in urban wastewater: Removal, mass load and environmental risk after a secondary treatment - A 646 review. Science of The Total Environment 429(0), 123-155.

647 Watanabe, H., Tamura, I., Abe, R., Takanobu, H., Nakamura, A., Suzuki, T., Hirose, A., 648 Nishimura, T. and Tatarazako, N. (2015) Chronic toxicity of an environmentally relevant 649 mixture of pharmaceuticals to three aquatic organisms (alga, daphnid, and fish). Environmental 650 Toxicology and Chemistry, n/a-n/a.

651 Winker, M., Faika, D., Gulyas, H. and Otterpohl, R. (2008a) A comparison of human 652 pharmaceutical concentrations in raw municipal wastewater and yellowwater. Science of The 653 Total Environment 399(1-3), 96-104.

654 Winker, M., Tettenborn, F., Faika, D., Gulyas, H. and Otterpohl, R. (2008b) Comparison of 655 analytical and theoretical pharmaceutical concentrations in human urine in Germany. Water 656 Research 42(14), 3633-3640.

657 Wood, A., Blackhurst, M., Hawkins, T., Xue, X., Ashbolt, N. and Garland, J. (2015) Cost658 effectiveness of nitrogen mitigation by alternative household wastewater management 659 technologies. Journal of Environmental Management 150, 344-354.

660 Zhang, R., Sun, P., Boyer, T.H., Zhao, L. and Huang, C.-H. (2015) Degradation of 661 Pharmaceuticals and Metabolite in Synthetic Human Urine by UV, UV/H2O2, and UV/PDS. 662 Environmental Science \& Technology 49(5), 3056-3066.

663

664

665 
Table 1. Capital and operation and management (O\&M) costs, net present value (NPV) for each urine treatment scenario; negative values indicate cost, positive values indicate revenue

\begin{tabular}{|c|c|c|c|c|c|c|c|c|}
\hline Capital Costs & Awwt & BwwT,03 & Ctruck,landfill & D truck,regen & Esewer,landfill & $F_{\text {sewer,regen }}$ & Gdecen,landfill & Hdecen,regen \\
\hline Fixtures $^{\mathrm{a}}$ & $-\$ 1,590,000$ & $-\$ 1,590,000$ & $-\$ 4,880,000$ & $-\$ 4,880,000$ & $-\$ 4,880,000$ & $-\$ 4,880,000$ & $-\$ 4,880,000$ & $-\$ 4,880,000$ \\
\hline Vacuum sewer & $\$ 0$ & $\$ 0$ & $\$ 0$ & $\$ 0$ & $-\$ 651,500$ & $-\$ 651,500$ & $\$ 0$ & $\$ 0$ \\
\hline Urine piping & $\$ 0$ & $\$ 0$ & $-\$ 171,000$ & $-\$ 171,000$ & $-\$ 171,000$ & $-\$ 171,000$ & $-\$ 171,000$ & $-\$ 171,000$ \\
\hline Urine storage $^{\mathrm{b}}$ & $\$ 0$ & $\$ 0$ & $-\$ 1,300,000$ & $-\$ 1,300,000$ & $-\$ 1,300,000$ & $-\$ 1,300,100$ & $-\$ 69,000$ & $-\$ 69,000$ \\
\hline Ozone system & $\$ 0$ & $-\$ 2,810,000$ & $\$ 0$ & $\$ 0$ & $\$ 0$ & $\$ 0$ & $\$ 0$ & $\$ 0$ \\
\hline Fiberglass IX vessel & $\$ 0$ & $\$ 0$ & $-\$ 8,600$ & $-\$ 8,600$ & $-\$ 8,600$ & $-\$ 8,600$ & $-\$ 8,600$ & $-\$ 8,600$ \\
\hline Struvite storage & $\$ 0$ & $\$ 0$ & $-\$ 400$ & $-\$ 400$ & $-\$ 400$ & $-\$ 400$ & $-\$ 400$ & $-\$ 400$ \\
\hline \multicolumn{9}{|l|}{ O\&M Costs } \\
\hline Diesel fuel $^{\mathrm{C}}$ & $\$ 0$ & $-\$ 160$ & $-\$ 2,900$ & $-\$ 3,000$ & $-\$ 4$ & $-\$ 100$ & $-\$ 12$ & $-\$ 100$ \\
\hline Potable flush water & $-\$ 234,000$ & $-\$ 234,000$ & $-\$ 1,300$ & $-\$ 1,300$ & $-\$ 1,300$ & $-\$ 1,300$ & $-\$ 1,300$ & $-\$ 1,300$ \\
\hline Electricity at WWTP ${ }^{\mathrm{d}}$ & d $-\$ 36,300$ & $-\$ 36,300$ & $-\$ 1,700$ & $-\$ 1,700$ & $-\$ 1,700$ & $-\$ 1,700$ & $-\$ 1,700$ & $-\$ 1,700$ \\
\hline Ozone operation ${ }^{\mathrm{e}}$ & $\$ 0$ & $-\$ 19,900$ & $\$ 0$ & $\$ 0$ & $\$ 0$ & $\$ 0$ & $\$ 0$ & $\$ 0$ \\
\hline Vacuum sewer & $\$ 0$ & $\$ 0$ & $\$ 0$ & $\$ 0$ & $-\$ 36,900$ & $-\$ 36,900$ & $\$ 0$ & $\$ 0$ \\
\hline IX resin & $\$ 0$ & $\$ 0$ & $-\$ 52,800$ & $-\$ 52,800$ & $-\$ 52,800$ & $-\$ 52,800$ & $-\$ 52,800$ & $-\$ 52,800$ \\
\hline IX operation ${ }^{f}$ & $\$ 0$ & $\$ 0$ & $-\$ 1,500$ & $-\$ 9,000$ & $-\$ 1,500$ & $-\$ 9,000$ & $-\$ 1,500$ & $-\$ 9,000$ \\
\hline Struvite revenue $\mathrm{g}$ & $\$ 0$ & $\$ 0$ & $\$ 12,100$ & $\$ 12,100$ & $\$ 12,100$ & $\$ 12,100$ & $\$ 12,100$ & $\$ 12,100$ \\
\hline NPV $(\$ M)^{\mathrm{h}}$ & $-\$ 10.1$ & $-\$ 14.6$ & $-\$ 10.5$ & $-\$ 10.7$ & $-\$ 12.2$ & $-\$ 12.4$ & $-\$ 8.83$ & $-\$ 9.05$ \\
\hline $2.5 \% \mathrm{CI}$ & $-\$ 36.2$ & $-\$ 41.5$ & $-\$ 16.0$ & $-\$ 16.7$ & $-\$ 18.3$ & $-\$ 18.9$ & $-\$ 11.2$ & $-\$ 11.8$ \\
\hline $97.5 \% \mathrm{CI}$ & $-\$ 7.47$ & $-\$ 11.9$ & $-\$ 7.60$ & $-\$ 7.68$ & $-\$ 9.28$ & $-\$ 9.40$ & $-\$ 7.04$ & $-\$ 7.12$ \\
\hline
\end{tabular}

${ }^{a}$ Cost of conventional toilets and urinals (Scenarios A and B) or urine diverting flush toilets and waterless urinals (Scenarios C-F)

${ }^{\mathrm{b}}$ Includes centralized (Scenarios C and D) and decentralized (Scenarios C-F) urine storage

${ }^{c}$ Cost of diesel for all unit processes (e.g., ozonation process, urine, resin disposal to landfill or brine disposal to cement kiln plant, and/or struvite collection)

${ }^{\mathrm{d}}$ Only pertains to electricity use based on influent flow at wastewater treatment

e Includes liquid oxygen, potable water, diesel, and energy requirements

${ }^{\mathrm{f}}$ Includes potable water, chemical (e.g., $\mathrm{NaCl}$, methanol), and energy requirements

${ }^{g}$ Net balance of $\mathrm{MgO}$ costs for struvite precipitation and value of struvite

${ }^{\mathrm{h}} 60$ year planning horizon and 3\% interest rate

i $3 \%$ interest rate 


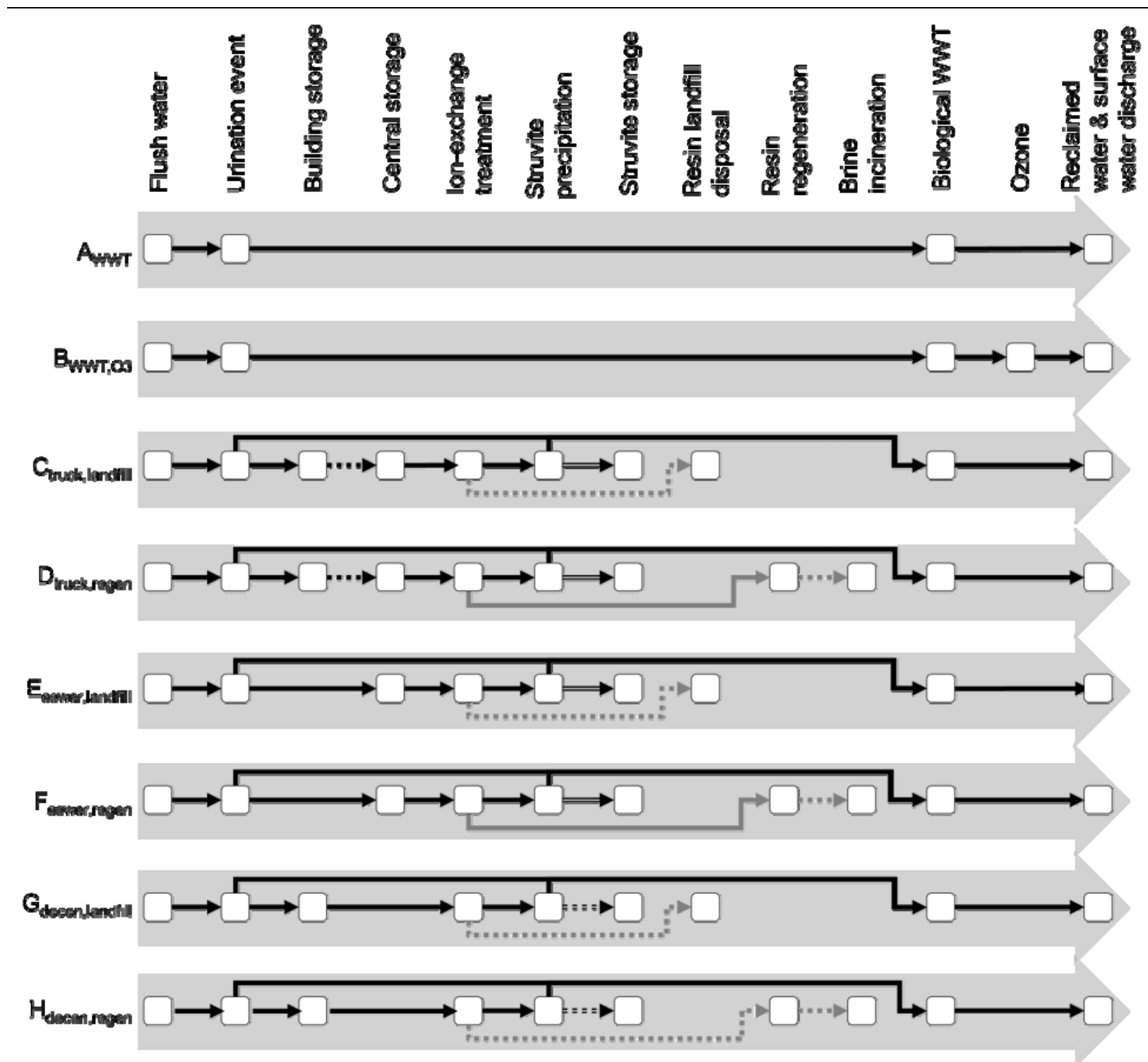

Figure 1. Treatment schematic for scenarios A-H (light gray horizontal arrows) and contributing processes. Single black lines represent urine flow, grey lines represent ion-exchange resin flow, and double black lines represent struvite flow. The solid lines indicate transport through pipes and dashed lines represent road transport by truck. 


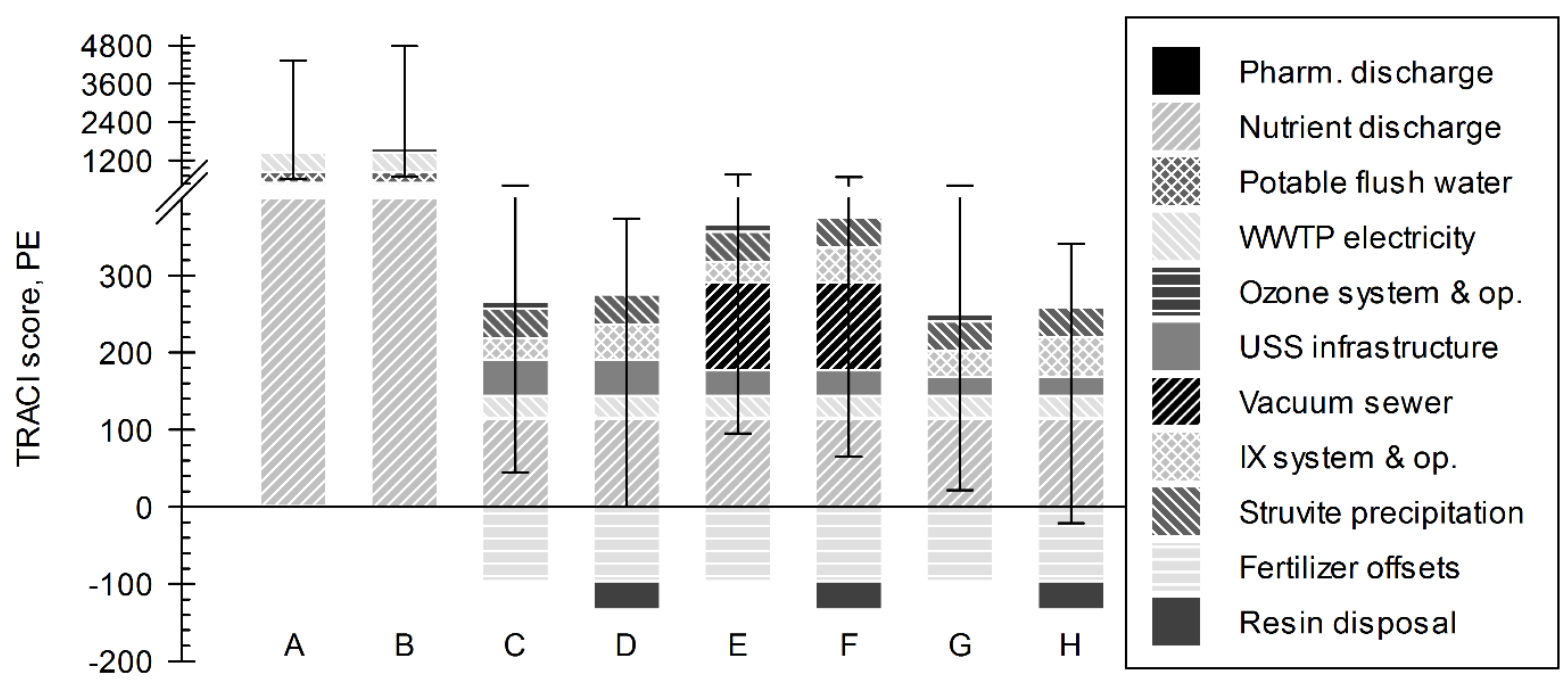

Figure 2. Normalized TRACI impact score for all scenarios (a) centralized wastewater treatment scenarios (Awwt, Bwwт,03), and (b) urine source separation scenarios (C-H). Each colored bar represents input processes (e.g., potable water, electricity use at the WWTP, urine source separation (USS) infrastructure), avoided impacts (e.g., fertilizer offsets, brine incineration), and generated impacts (e.g., nutrient discharge, pharmaceutical discharge). The brackets around each error bar represent the 95\% confidence interval resulting from Ecoinvent database distributions from the Monte Carlo uncertainty analysis. 


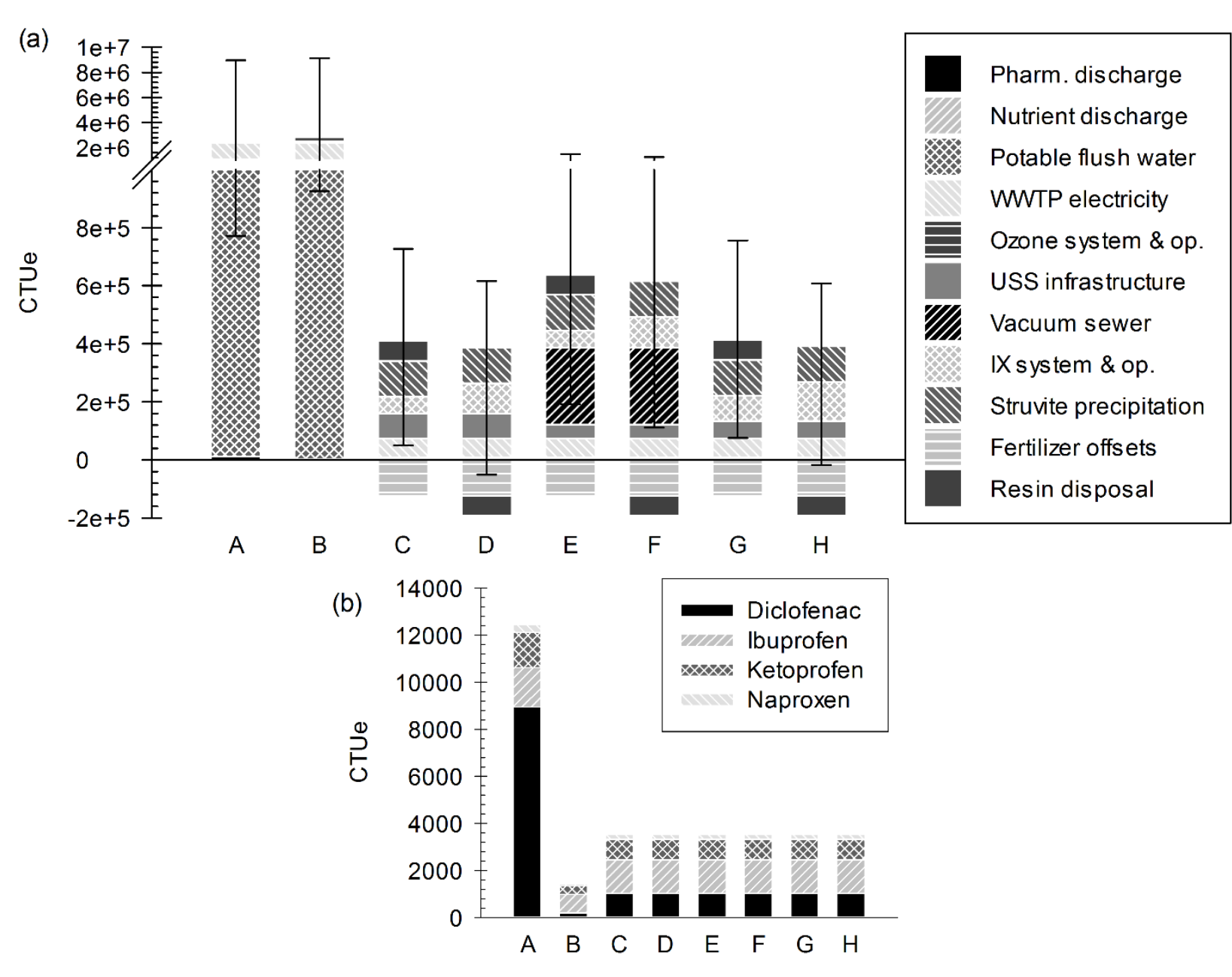

Figure 3. Comparison of ecotoxicity impact (CTUe $=\mathrm{PAF} \cdot \mathrm{m}^{3} \cdot$ day) due to (a) contributing processes (e.g., flush water, urine transport) and generated emissions (e.g., nutrient discharge, pharmaceutical discharge) and avoided impacts (e.g., fertilizer offsets, brine incineration) in each scenario and (b) pharmaceutical emissions only. The brackets around each error bar represent the 95\% confidence interval resulting from Ecoinvent database distributions from the Monte Carlo uncertainty analysis. 


\section{Graphical Abstract}

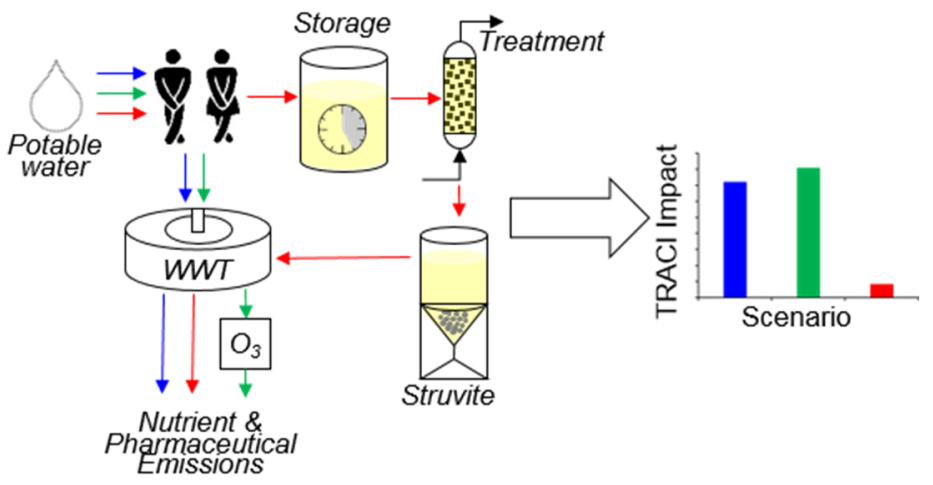

